\title{
Nanocomposites Impacts on Electrical Field Distribution Inside XLPE Power Cables
}

\author{
A.Thabet \\ Nanotechnology Research Center, Aswan University, Egypt \\ College of Engineering, Qassim University, KSA \\ athm@aswu.edu.eg \\ Abdel-Moamen M. A \\ Faculty of Energy Engineering, Aswan University, Egypt \\ abdelmoamen@gmail.com
}

\begin{abstract}
This paper presents the electrical field stress in new cross-linked polyethylene (XLPE) nanocomposites in case of containing different partial discharges under high voltages. It has been investigated on the effect of variant nanoparticles for controlling on the electrical field distribution inside single-core power cables insulation, especially, in case of presence voids of air, water and cupper impurities with different shapes (cylinder, sphere and ellipse) inside insulation of single-core power cables. The electrical field distribution in power cable insulation and inside voids has been measured by finite element method (FEM). This research success to design different patterns of Crosslinked polyethylene insulation materials for enhancing the dielectric properties within void and inside insulator according to type and concentration of nanoparticles.
\end{abstract}

Keywords - Voids; electrical stress; XLPE Cables; FEM; Nanoparticles.

\section{INTRODUCTION}

Partial discharge (PD) in electrical power cables is one of the main causes for insulation disintegration and localized electrical discharges as well as defects inside the insulation material of electrical power cables. Partial discharges demean the insulation of cable to failed point in the power cable. PD usually occurs due to voids inside the insulation material of the electrical power cables [1-3]. Degradation in insulation materials is caused by electrical, chemical and mechanical stress that causes of partial discharges within the cable and lead to cable failure [4-6]. XLPE insulation in power cables has much better electrical, thermal, and mechanical performances than oil paper insulation in power cables. The manufacturing of XLPE cables needs to avoid defects of insulation and joints of power cables which are the vital components in power cable manufacturing. Due to the existing defects in the insulation and joints of power cables, they may lead to a system fault, such as partial discharge cable joints, the cable joints consider the weakest points in power cables transmission lines [7-9]. Partial discharge study provides a useful tool to obtain information about discharging defects in high-voltage equipment.

Nanocomposites materials are formed by the homogenous dispersion of nano-sized inorganic particles into a polymeric matrix, and the special properties come about because of the strong interaction between the organic and

\author{
M. Fouad \\ Nag Hammadi Hydro Power Plant \\ Hydro Power Plant Generation Company, Egypt \\ fouad1284@gmail.com
}

A. El-Nobi

Faculty of Energy Engineering, Aswan University, Egypt ahmednoby100@yahoo.com

inorganic phases, which is attributed to the very large active surface of the nano-sized particles [10-15]. Theoretical models are capable of predicting the life and reliability of $\mathrm{HV}$ cable systems, including accessories, as functions of the applied stresses, would be of interest to cable manufacturers and transmission system operators. The service lifetime of an insulation is a mathematical relationship between time to failure and the level of one or more of the applied stresses. The life time model becomes a reliability model if it is also capable of predicting the reliability of the insulation after a certain time under the applied stresses [16-17]. This paper focus on analysing the electric fields distribution in new multi-nanocomposites and studying the effects of different types of multi-nanocomposites for industrial progress power cables applications. Also, it has been studied the effect of multi-nanoparticles arrangement in the new suggested electrical nanocomposites materials. It has been simulated the electric field distribution to explain ability of new nanocomposites and multiple nanocomposites materials for enhancing single core power cables insulation. The aim of this paper is enhancing insulation performance of single-core power cables that are exposed to manufacture defects like air voids, water voids and impurities, etc. Thus, this paper has been studied the electrical stress distribution in presence of different shapes of voids (cylinder - sphere - ellipse) in case of using individual and multiple nanoparticles techniques to insulation of single-core power cables.

\section{INSULATION MATERIALS DESIGN}

Power law relationships are used in dielectric modelling of composite systems by using individual nanoparticles; so that, the composite system have three components as follow matrix, nanoparticle and interphase region [18]. Moreover, the interphase region is depending on the nanoparticle volume fraction, the nanoparticle surface area and the thickness of the interphase region surrounding each nanoparticle particle [19-21]. Whatever, it has been suggested a new multi-nanoparticles technique for developing the electric field strength and dielectric properties of polymer [22]. Estimation of interphase thickness is further advanced based on ref. [23-25]. Figure 1 clarifies the nanoparticles come close together, and the interphase regions surrounding 
each nanoparticle begin to overlap hence, decreasing the effective interphase volume fraction has been occurred.
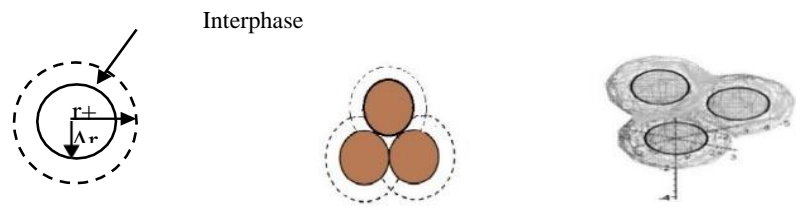

Fig. 1. Interphase region surrounding the multi-nanoparticle particles in multi-nanocomposites system

\section{POWER CABle Sumilation Model}

It is recognized by the theory that in a single-core cable having $(\mathrm{r})$ radius of core and $(\mathrm{R})$ inner radius of insulation, the potential gradient $(\mathrm{g})$ at a distance $(\mathrm{x})$ from position of the core center inside the dielectric material

$\mathrm{g}=\frac{\mathrm{q}}{2 \pi \varepsilon \mathrm{x}}=\xi \mathrm{x}$

Which, $\xi \mathrm{x}$ is the electrical field intensity, $\varepsilon$ is the dielectric permittivity of the material, $q$ is the charge per unit length.

Here, the maximum stress in dielectric material occurs at the minimum value of the radius (here, $x=r$ ) So,

$$
\xi \mathrm{x}=\frac{\mathrm{V}}{\mathrm{r} \log _{\mathrm{e}} \frac{\mathrm{R}}{\mathrm{r}}}
$$

Electric field calculation requires solution of Laplace and Poisson equations. In Past studies, electric field is defined as a source of corona around conductor imperfect partial discharge and early insulation failure. by assuming there is no free surface change at the insulation surface and void boundary, Internal and External electric field of cylindrical void is calculated by following equations [26].

$$
\begin{aligned}
& E(r)=E_{\mathrm{o}}\left(i_{\mathrm{r}}\left[1+\left(\frac{\varepsilon_{\mathrm{r}}-\varepsilon_{\mathrm{o}}}{\varepsilon_{\mathrm{r}}+\varepsilon_{\mathrm{o}}}\right) \times \frac{r_{\mathrm{v}}{ }^{2}}{r^{2}}\right] \cos \theta-i \Theta[1+\right. \\
& \left.\left(\frac{\varepsilon_{\mathrm{r}}-\varepsilon_{\mathrm{o}}}{\varepsilon_{\mathrm{r}}+\varepsilon_{\mathrm{o}}}\right) \times \frac{r_{\mathrm{v}}{ }^{2}}{r^{2}}\right] \sin \theta \quad \text { for }\left(\mathrm{r}>\mathrm{r}_{\mathrm{v}}\right) \\
& E(r)=E_{\mathrm{o}}\left(\frac{2 \varepsilon_{\mathrm{o}}}{\varepsilon_{\mathrm{r}}+\varepsilon_{\mathrm{o}}}\right)\left(i_{\mathrm{r}} \cos \theta-i \theta \sin \theta\right) \text { for }\left(0 \leq \mathrm{r}<\mathrm{r}_{\mathrm{v}}\right)
\end{aligned}
$$

Internal and External electric field of spherical void is calculated by following equations

$$
\begin{aligned}
& \mathrm{E}(\mathrm{r})=\mathrm{E}_{\mathrm{o}}\left(\mathrm{i}_{\mathrm{r}}\left[-1-\left(\frac{\varepsilon_{\mathrm{r}}-\varepsilon_{\mathrm{o}}}{\varepsilon_{\mathrm{r}}+2 \varepsilon_{\mathrm{o}}}\right) \times \frac{2 \mathrm{r}_{\mathrm{v}}{ }^{3}}{\mathrm{r}^{3}}\right] \cos \theta+\mathrm{i} \theta[1-\right. \\
& \left.\left(\frac{\varepsilon_{\mathrm{r}}-\varepsilon_{\mathrm{o}}}{\varepsilon_{\mathrm{r}}+2 \varepsilon_{\mathrm{o}}}\right) \times \frac{2 \mathrm{r}_{\mathrm{v}}{ }^{3}}{\mathrm{r}^{3}}\right] \sin \theta \quad \text { for }\left(\mathrm{r}>\mathrm{r}_{\mathrm{v}}\right) \\
& E(r)=E_{\mathrm{o}}\left(-\left(\frac{3 \varepsilon_{\mathrm{o}}}{\varepsilon_{\mathrm{r}}+2 \varepsilon_{\mathrm{o}}}\right)\left(i_{\mathrm{r}} \cos \theta-i \theta \sin \theta\right) \text { for }\left(0 \leq \mathrm{r}<\mathrm{r}_{\mathrm{v}}\right)\right.
\end{aligned}
$$

Where, $r_{v}$ is radius of void, $r$ distance from void center, $E_{\circ}$ uniform dielectric

field.

But all the times irregular problem geometry for void is so complicated that analytical solution is so hard. so, researches tried to find new calculating methods to obtain electric field. FEM method is chosen for computation use. Electric field equations solution by this method is based on Maxwell equations with boundary conditions.

The effective dielectric constant of the inclusion and interphase could be expressed for individual nanocomposite model that contains an interphase region according to [19-21] as: $\varepsilon_{\text {effi }}^{\beta}=\varphi_{\mathrm{i}} \varepsilon_{\mathrm{i}}^{\beta}+\varphi_{\mathrm{phi}} \varepsilon_{\mathrm{phi}}^{\beta}+\varphi_{\mathrm{m}} \varepsilon_{\mathrm{m}}^{\beta}$

Whatever, the effective dielectric constant of the inclusion and interphase could be expressed for multiple Nanocomposite model that contains an interphase region according to [22] as:

$\varepsilon_{\mathrm{effj}}^{\beta}=\varphi_{\mathrm{j}} \varepsilon_{\mathrm{j}}^{\beta}+\varphi_{\mathrm{phij}} \varepsilon_{\mathrm{phij}}^{\beta}+\varphi_{\mathrm{effi}} \varepsilon_{\mathrm{effi}}^{\beta}$

Where, $\varphi_{\mathrm{i}}$ is the volume fraction of first filler component of the nano-composite system

$\varphi_{\mathrm{phi}}$ is the volume fraction of the interphase region component of the nano-composite system

$\varphi_{\mathrm{m}}$ is the volume fraction of the matrix component of the nano-composite system

$\varepsilon_{\text {effi }}$ is the permittivity of the nano-composite system.

$\varepsilon_{\mathrm{i}}$ is the filler permittivity of the nano-composite system.

$\varepsilon_{\text {phi }}$ is the interphase permittivity of the nano-composite system.

$\varepsilon_{\mathrm{m}}$ is the matrix permittivity of the nano-composite system.

$\varphi_{\mathrm{j}}$ is the volume fraction of second filler component of the nano-composite system.

$\varphi_{\text {phij }}$ is the volume fraction of the interphase region component of the nano-composite system.

$\varphi_{\text {effi }}$ is the volume fraction of the matrix component of the nano-composite system

$\varepsilon_{\text {effj }}$ is the permittivity of the nano-composite system.

$\varepsilon_{\mathrm{j}}$ is the second filler permittivity of the nano-composite system.

$\varepsilon_{\text {phij }}$ is the interphase permittivity of the nano-composite system.

$\varepsilon_{\text {effi }}$ is the dielectric permittivity of the individual nanocomposites system.

$\beta=0.33$

\section{MODEL CONFIGURATION}

In this research, it has been investigated single-core power cable configuration that is shown in Fig. 2. The model configuration setup according to standard dimensions designed by NEXANS Energy Networks Company, Design Standards 6622 - BS 7835 [27]. TABEL I illustrate the model parameter of single-core power cables. The void diameter is considered $1 \mathrm{~mm}$ located between the conductor surface and the insulation inner surface [28]. Finite Element Methods Magnetics (FEMM) software is used for this simulation. Finite Element Method Magnetics (FEMM) software is a finite element package. This software is used for disbanding two-dimensional planar and axisymmetric problems in electrostatics, current flow, heat flow and low frequency magnetics [30]. The FEMM used method flow chart clarifying in Fig. 3. and Dielectric Constant of New Crosslinked polyethylene nanocomposites and multinanocomposites materials shown in TABLE II. 


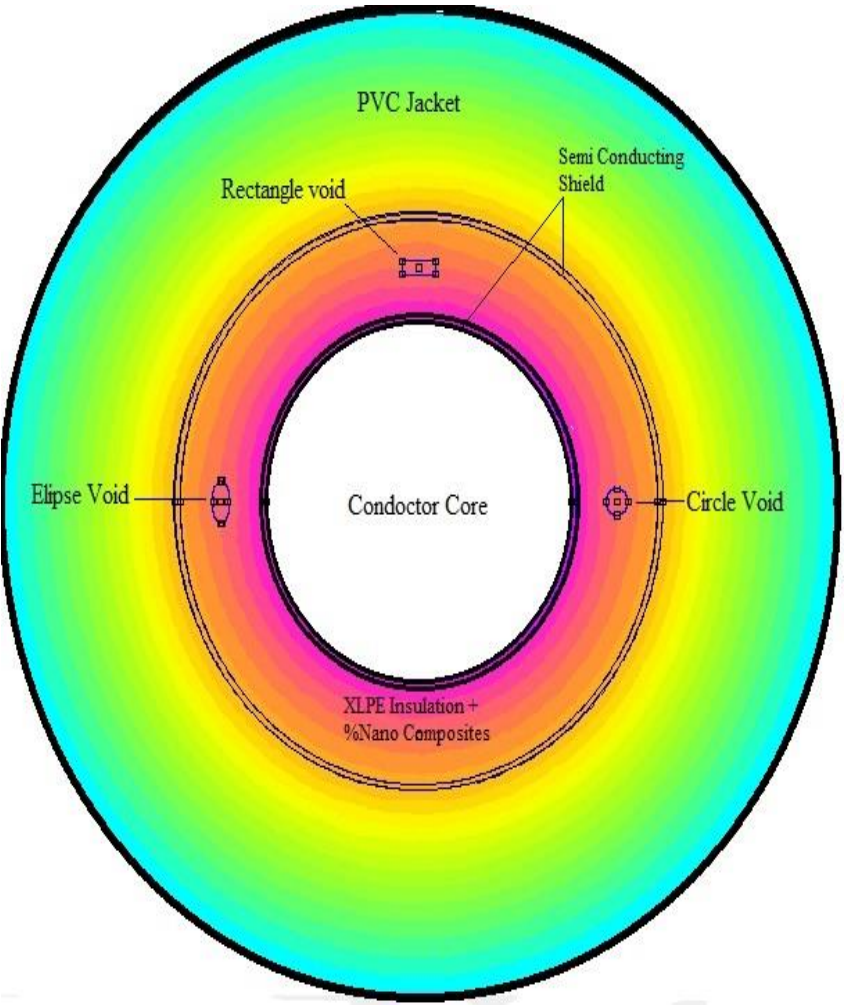

Fig. 2. Cross section of single core cables with Multi-voids

TABLE I. Configuration of Single Core CABLe [27- 30]

\begin{tabular}{|c|c|}
\hline Specification & Rating \\
\hline Rated voltage $(\mathrm{kV})$ & 11 \\
\hline Number core & 1 \\
\hline Cross-sectional area of conductor $\left(\mathrm{mm}^{2}\right)$ & 150 \\
\hline Diameter over conductor $(\mathrm{mm})$ & 14.3 \\
\hline Diameter over insulation $(\mathrm{mm})$ & 22.2 \\
\hline Overall diameter $(\mathrm{mm})$ & 38 \\
\hline Insulation dielectric constant (XLPE) & 2.4 \\
\hline Water permittivity & 81 \\
\hline Air permittivity & 1 \\
\hline Cupper impurity permittivity & 5.6 \\
\hline Radius of bubble (mm) & 0.5 \\
\hline
\end{tabular}

TABLE II. DIELECTRIC CONSTANT OF NANOPARTICLES, NEW CROSS-LINKED POLYETHYLENE (XLPE) NANOCOMPOSITES AND MULTINANOCOMPOSITES MATERIALS

\begin{tabular}{|c|c|}
\hline Materials & Dielectric constant \\
\hline Pure XLPE & 2.4 \\
\hline $\mathrm{BaTiO}_{3}$ & 3.8 \\
\hline $\mathrm{TiO}_{2}$ & 11 \\
\hline Silica & 3 \\
\hline $\mathrm{MgO}$ & 9.7 \\
\hline $\mathrm{Al}_{2} \mathrm{O}_{3}$ & 9.1 \\
\hline $\mathrm{Fe}_{2} \mathrm{O}_{3}$ & 25 \\
\hline 10 wt. $\% \mathrm{BaTiO}_{3} / \mathrm{XLPE}$ & 2.536 \\
\hline$\left(10 \mathrm{wt} . \% \mathrm{BaTiO}_{3}+15 \mathrm{wt} . \%\right.$ Silica $) / \mathrm{XLPE}$ & 2.638 \\
\hline$\left(10\right.$ wt. $\% \mathrm{BaTiO}_{3}+15$ wt. $\left.\% \mathrm{MgO}\right) / \mathrm{XLPE}$ & 26.73 \\
\hline$\left(10 \mathrm{wt} . \% \mathrm{BaTiO}_{3}+15 \mathrm{wt} \mathrm{Fe}_{2} \mathrm{O}_{3}\right) / \mathrm{XLPE}$ & 45.45 \\
\hline$\left(10\right.$ wt. $\% \mathrm{BaTiO}_{3}+15$ wt. $\left.\% \mathrm{TiO}_{2}\right) / \mathrm{XLPE}$ & 3.697 \\
\hline $10 \mathrm{wt} . \% \mathrm{TiO}_{2} / \mathrm{XLPE}$ & 3.152 \\
\hline$\left(10 \mathrm{wt} . \% \mathrm{TiO}_{2}+15 \mathrm{wt} . \%\right.$ Silica $) / \mathrm{XLPE}$ & 3.117 \\
\hline$\left(10 \mathrm{wt} . \% \mathrm{TiO}_{2}+15\right.$ wt. $\left.\% \mathrm{MgO}\right) / \mathrm{XLPE}$ & 23.77 \\
\hline$\left(10\right.$ wt. $\% \mathrm{TiO}_{2}+15$ wt. $\left.\% \mathrm{Fe}_{2} \mathrm{O}_{3}\right) / \mathrm{XLPE}$ & 43.84 \\
\hline$\left(10\right.$ wt. $\% \mathrm{TiO}_{2}+15$ wt. $\left.\% \mathrm{BaTiO}_{3}\right) / \mathrm{XLPE}$ & 3.225 \\
\hline $10 \mathrm{wt} . \% \mathrm{Al}_{2} \mathrm{O}_{3} / \mathrm{XLPE}$ & 4.38 \\
\hline (10wt. $\% \mathrm{Al}_{2} \mathrm{O}_{3}+15$ wt. $\%$ Silica)/ XLPE & 4.034 \\
\hline$\left(10\right.$ wt. $\% \mathrm{Al}_{2} \mathrm{O}_{3}+15$ wt. $\left.\% \mathrm{MgO}\right) / \mathrm{XLPE}$ & 19.37 \\
\hline$\left(10\right.$ wt. $\% \mathrm{Al}_{2} \mathrm{O}_{3}+15$ wt. $\left.\% \mathrm{Fe}_{2} \mathrm{O}_{3}\right) / \mathrm{XLPE}$ & 41.27 \\
\hline$\left(10\right.$ wt. $\% \mathrm{Al}_{2} \mathrm{O}_{3}+15$ wt. $\left.\% \mathrm{TiO}_{2}\right) / \mathrm{XLPE}$ & 5.461 \\
\hline
\end{tabular}

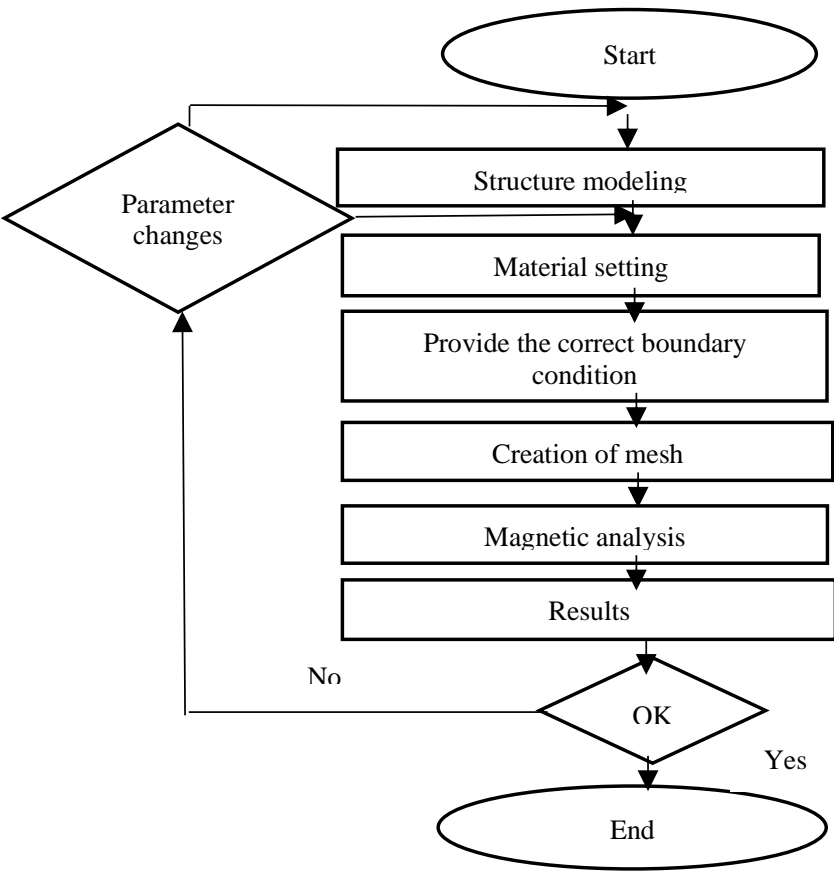

Fig. 3. FEMM program steps flow chart.

\section{RESULTS AND DISCUSSION}

Due to our needs for enhancing electric applications, it is important a getting new dielectric materials. Thus, the electric field stress can be controlled by changing relative permittivity of insulator material by adding individual or multiple nanoparticles to dielectrics. The following results illustrate the behaviour of electric field distribution inside pure and variant nanocomposites dielectrics of power cable which having (air - impurity - water) voids with different shapes (cylinder - sphere - ellipse).

\section{A. Effect of Air Voids Shapes Inside Modern Nanocomposites Insulation}

The following figures illustrate the behaviour of electric stress within variant pure and nanocomposites insulation of Cross-linked polyethylene in case of presence different air void shapes in single core power cable. Electric stress distribution is drawn around core axis passes through air voids. It has been observed that adding concentration of (10wt. $\% \mathrm{Al}_{2} \mathrm{O}_{3}+15$ wt. $\left.\% \mathrm{Fe}_{2} \mathrm{O}_{3}\right)$ nanoparticle to XLPE decreases the electric field distribution about $85.4 \%$ inside air sphere void, decreases the electric field distribution about $75.1 \%$ inside air cylinder void, decreases the electric field distribution about $80.3 \%$ inside air ellipse void and decreases the electric field distribution inside power cable insulation about $89.6 \%$ due to the effect of high dielectric constant and surface area of $\mathrm{Al}_{2} \mathrm{O}_{3}$ and $\mathrm{Fe}_{2} \mathrm{O}_{3}$ nanoparticles.

On the other side, it has been observed that adding concentration of (10wt. $\% \mathrm{Al}_{2} \mathrm{O}_{3}+15 \mathrm{wt} . \%$ Silica) nanoparticle to XLPE decreases the electric field distribution about $16.9 \%$ inside air sphere void, decreases the electric field distribution about $2.8 \%$ inside air cylinder void, decreases the electric field distribution about $8.9 \%$ inside air ellipse void and decreases the electric field distribution inside power cable insulation about $26.5 \%$ due to the effect of low dielectric constant and surface area of Silica nanoparticle. 
Other composite electric distribution assorted between them as shown in Fig. 4. Electric stress distribution inside air cylinder void shown in Fig.5 Electric stress distribution inside air ellipse void shown in Fig. 6.

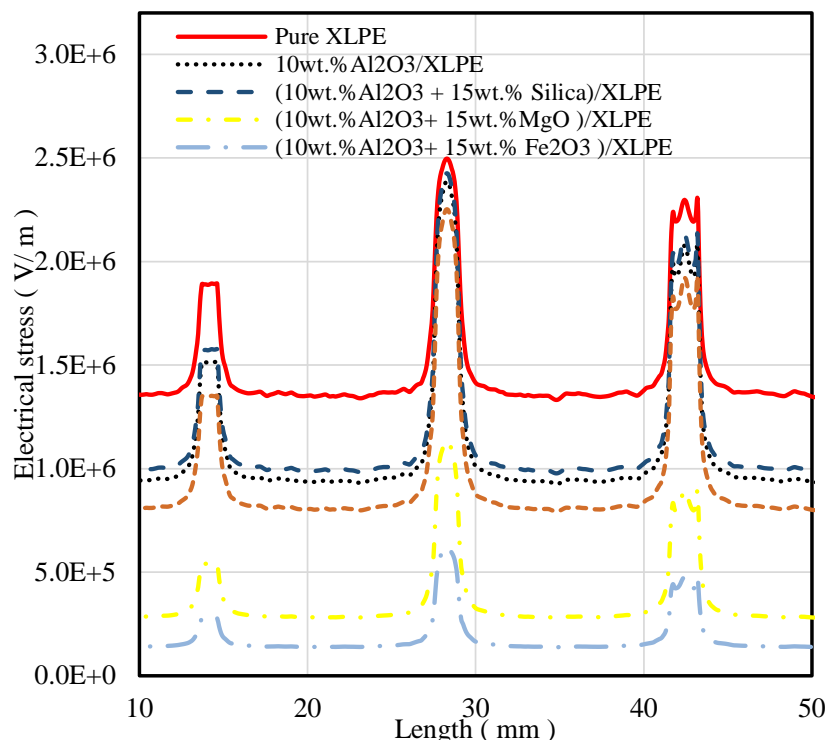

Fig. 4. Electric field distribution comparing pure XLPE with $\% \mathrm{AL}_{2} \mathrm{O}_{3}$ nanoparticles insulation material containing different shapes of air voids

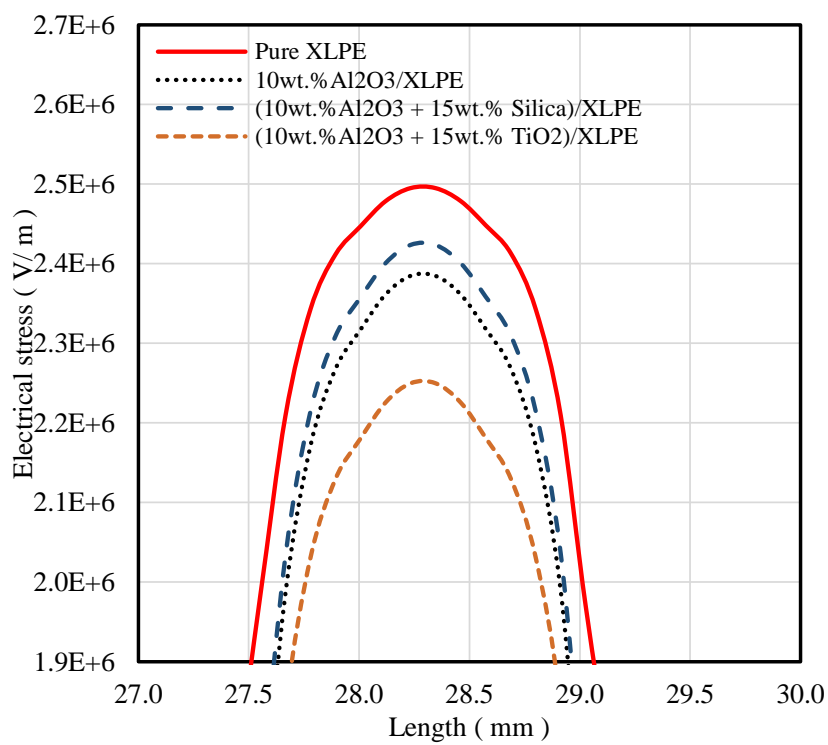

Fig. 5. Electric field distribution inside air cylinder void

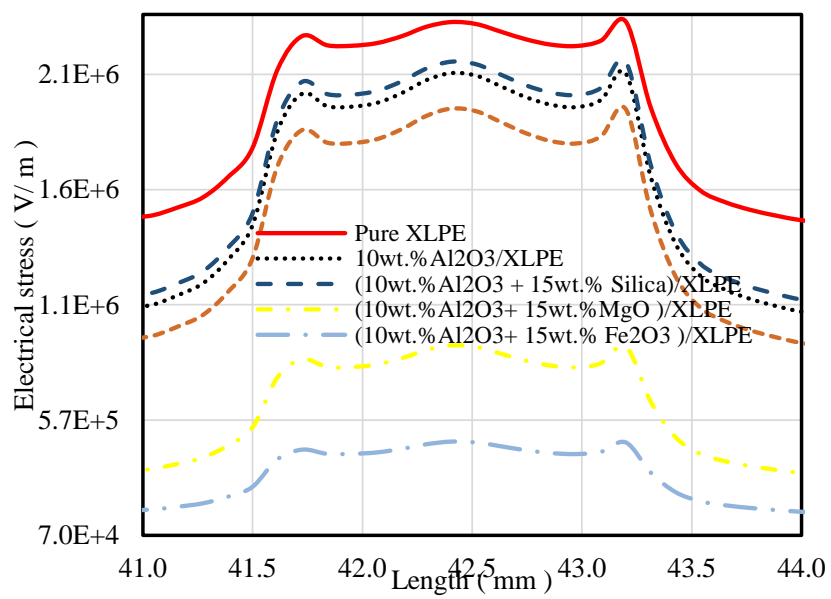

Fig. 6. Electric field distribution inside air ellipse void
Finally, it has been observed that adding concentration of $\left(10 \mathrm{wt} . \% \mathrm{BaTiO}_{3}+15 \mathrm{wt} . \% \mathrm{Fe}_{2} \mathrm{O}_{3}\right)$ nanoparticle to XLPE decreases the electric field distribution about $86.6 \%$ inside air sphere void, decreases the electric field distribution about $77.1 \%$ inside air cylinder void, decreases the electric field distribution about $81.9 \%$ inside air ellipse void and decreases the electric field distribution inside power cable insulation about $90.5 \%$ due to the effect of high dielectric constant and surface area of $\mathrm{Fe}_{2} \mathrm{O}_{3}$ nanoparticles.

On the other side, it has been observed that adding concentration of (10wt.\% $\quad \mathrm{BaTiO}_{3} \quad+15 \mathrm{wt} . \% \quad$ Silica) nanoparticle to XLPE decreases the electric field distribution about $2.6 \%$ inside air sphere void, increases the electric field distribution about $0.8 \%$ inside air cylinder void, decreases the electric field distribution about $0.9 \%$ inside air ellipse void and decreases the electric field distribution inside power cable insulation about $4.5 \%$ due to the effect of low dielectric constant and surface area of $\mathrm{BaTiO}_{3}$ and Silica nanoparticles.

Also, when adding concentration of (10wt.\% $\left.\mathrm{BaTiO}_{3}\right)$ nanoparticle to XLPE electric stress inside cable insulator be in higher value than adding concentration of (10wt.\% $\mathrm{BaTiO}_{3}+15 \mathrm{wt} . \%$ Silica) nanoparticles to XLPE and other composite electric distribution assorted between them as shown in Fig.7. Electric stress distribution inside air cylinder void shown in Fig.8. Electric stress distribution inside air ellipse void shown in Fig.9.

It has observed different behaviour to electric stress performance in case of adding multiple nanoparticles inside XLPE.

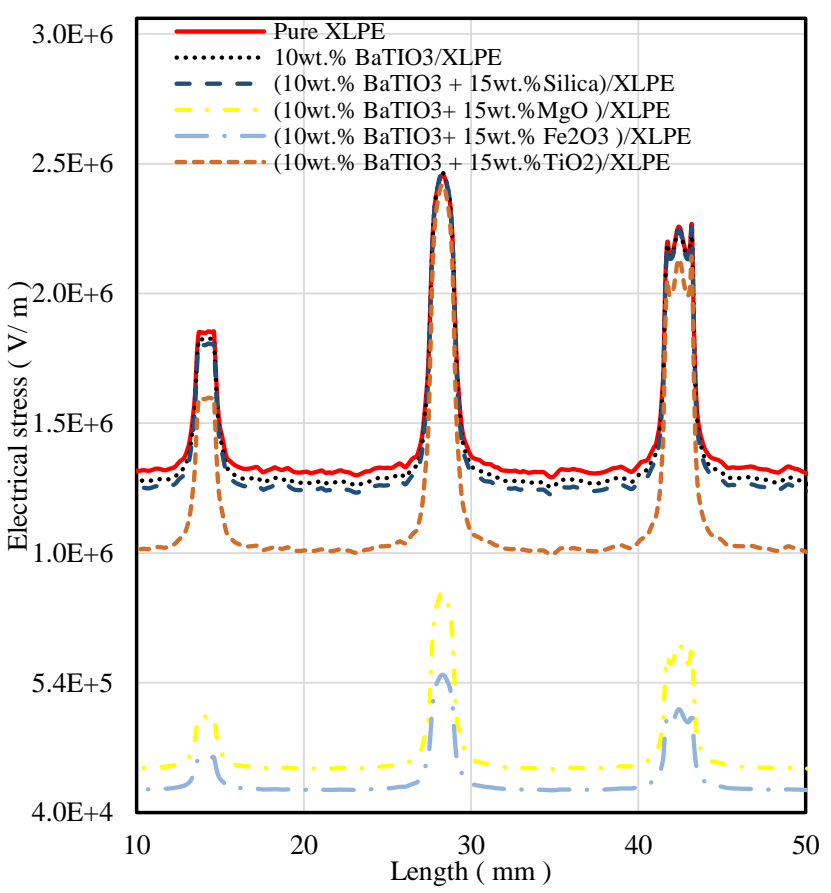

Fig. 7. Electric field distribution comparing pure XLPE with $\% \mathrm{BaTiO}_{3}$ nanoparticles insulation material containing different shapes of air void 


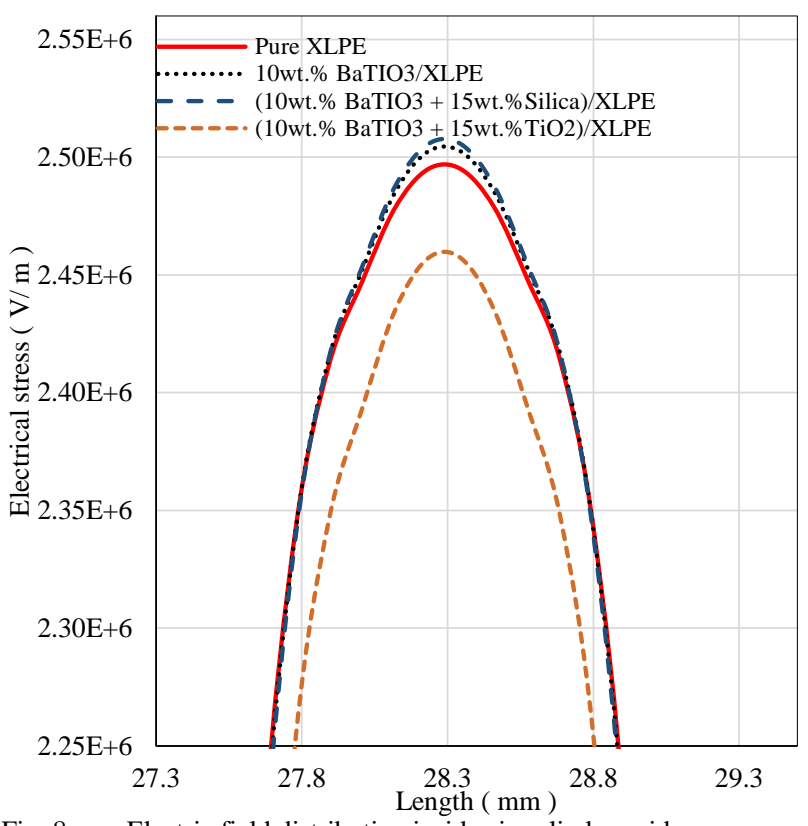

Fig. 8. Electric field distribution inside air cylinder void

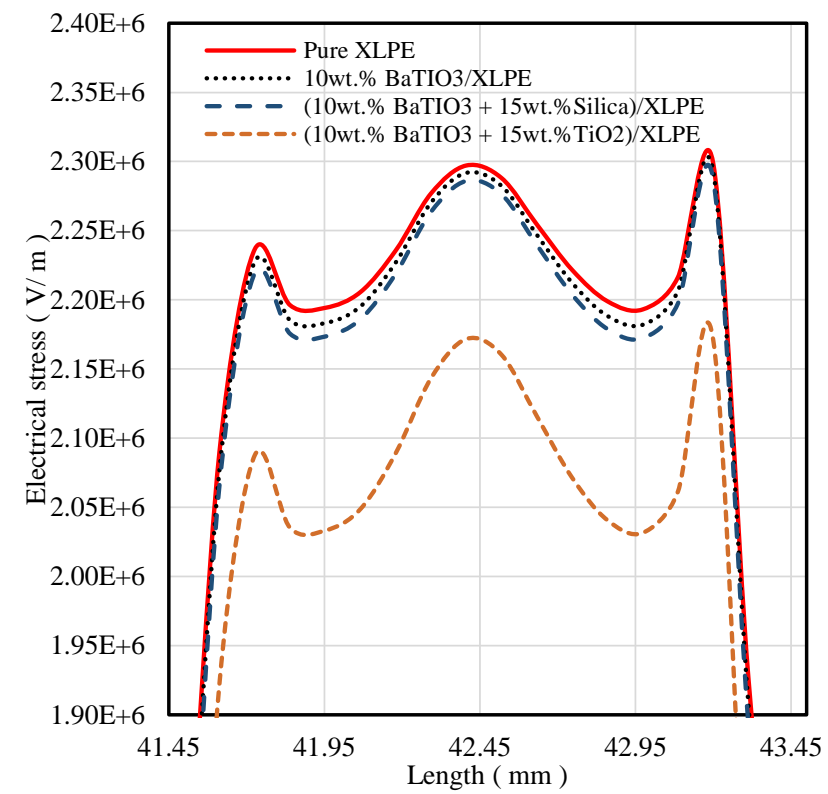

Fig. 9. Electric field distribution inside air ellipse void

\section{B. Effect of Water Voids Shapes Inside Modern Nanocomposites Insulation}

Following figures illustrate the behaviour of electric stress within variant New Cross-linked polyethylene insulation materials pure and nanocomposites in case of presence different water void shapes in single core power cable. Electric stress distribution is drawn around core axis passes through water voids.

It has been observed that adding concentration of (10wt. $\% \mathrm{Al}_{2} \mathrm{O}_{3}+15 \mathrm{wt} . \% \mathrm{Fe}_{2} \mathrm{O}_{3}$ ) nanoparticle to XLPE decreases the electric field distribution about $17.4 \%$ inside water sphere void, decreases the electric field distribution about $59.9 \%$ inside water cylinder void, decreases the electric field distribution about $41.9 \%$ inside water ellipse void and decreases the electric field distribution inside power cable insulation about $89.6 \%$ due to the effect of high dielectric constant and surface area of $\mathrm{Al}_{2} \mathrm{O}_{3}$ and $\mathrm{Fe}_{2} \mathrm{O}_{3}$ nanoparticles.
On the other side, it has been observed that adding concentration of $\left(10 \mathrm{wt} . \% \mathrm{Al}_{2} \mathrm{O}_{3}+15 \mathrm{wt} . \%\right.$ Silica $)$ nanoparticle to XLPE decreases the electric field distribution about 19.5\% inside water sphere void, decreases the electric field distribution about $21.8 \%$ inside water cylinder void, decreases the electric field distribution about $20.9 \%$ inside water ellipse void and decreases the electric field distribution inside power cable insulation about $26.5 \%$ due to the effect of low dielectric constant and surface area of Silica nanoparticle. It has been observed that adding concentration of $\left(10 \mathrm{wt} . \% \mathrm{Al}_{2} \mathrm{O}_{3}\right)$ nanoparticle to XLPE has decreased the electric stress inside cable insulator than adding concentration of ( $10 \mathrm{wt} . \% \mathrm{Al}_{2} \mathrm{O}_{3}+15 \mathrm{wt} . \%$ Silica $)$ nanoparticle to XLPE and other composite electric distribution assorted between them as shown in Fig.10. Electric stress distribution inside water cylinder void shown in Fig.11. Thus, the electric stress distribution inside water ellipse void shown in Fig.12.

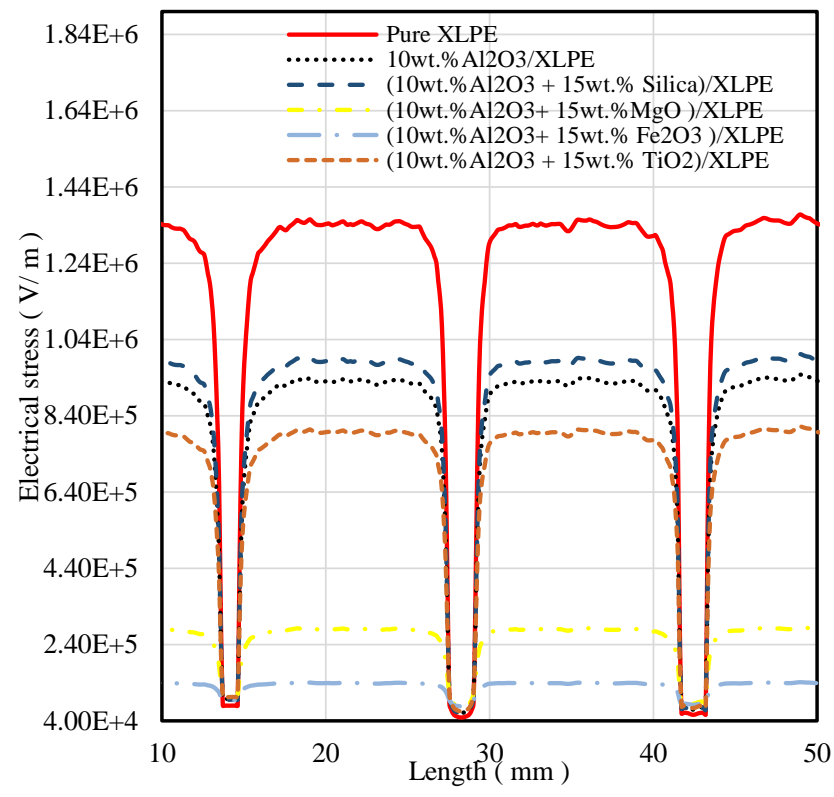

Fig. 10. Electric field distribution comparing pure XLPE with $\% \mathrm{AL}_{2} \mathrm{O}_{3}$ nanoparticles insulation material containing different shapes of water voids

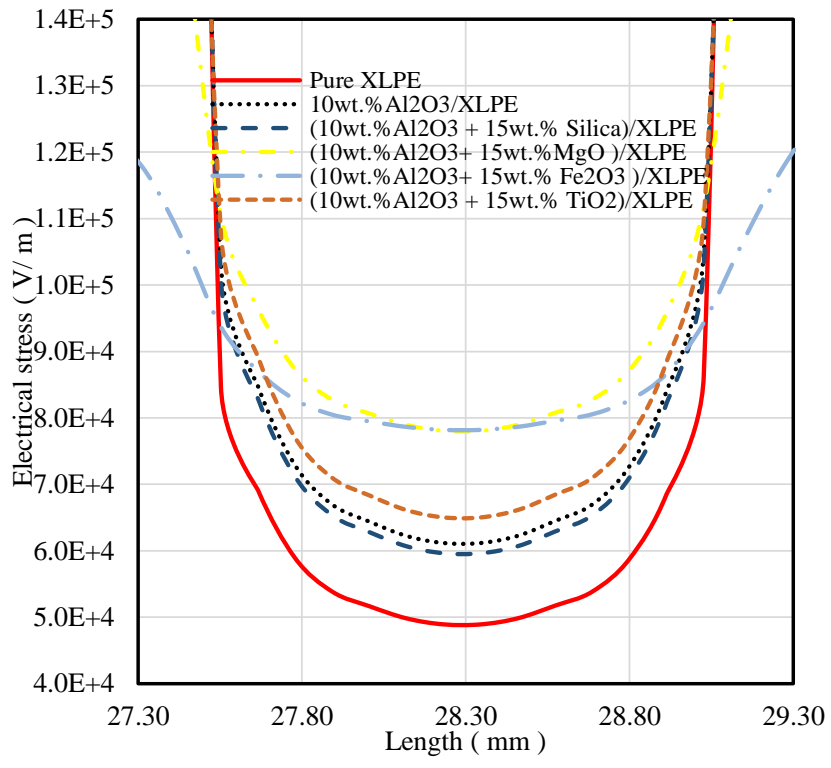

Fig. 11. Electric field distribution inside water cylinder void 


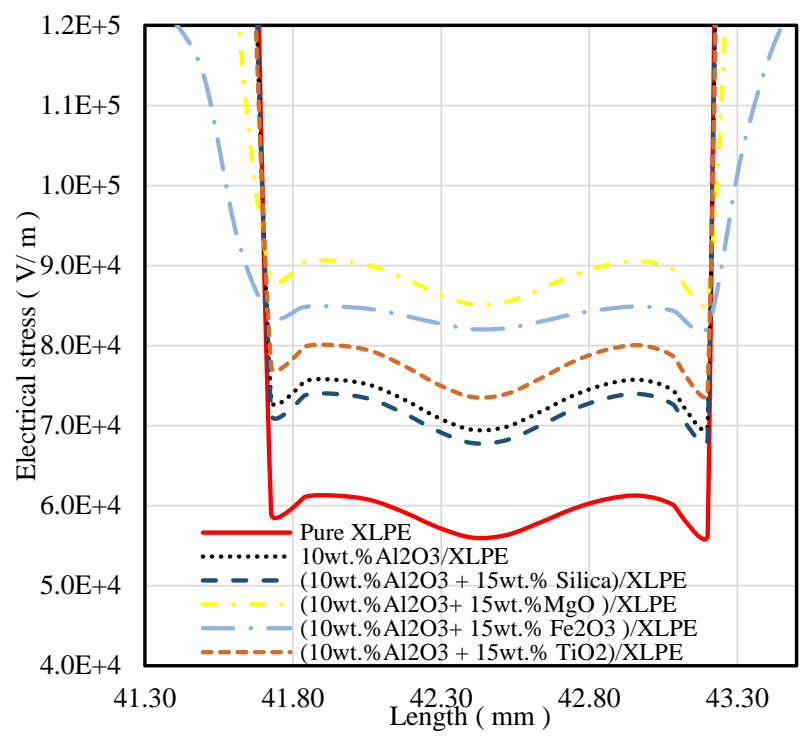

Fig. 12. Electric field distribution inside water ellipse void

Moreover, it has been observed that adding concentration of $\left(10 \mathrm{wt} . \% \mathrm{BaTiO}_{3}+15 \mathrm{wt} . \% \mathrm{MgO}\right)$ nanoparticle to XLPE decreases the electric field distribution about $30.3 \%$ inside water sphere void, decreases the electric field distribution about $61.1 \%$ inside water cylinder void, decreases the electric field distribution about $48.2 \%$ inside water ellipse void and decreases the electric field distribution inside power cable insulation about $84.4 \%$ due to the effect of high dielectric constant and surface area of $\mathrm{MgO}$ nanoparticle.

On the other side, it has been observed that adding concentration of $\left(10 \mathrm{wt} . \% \quad \mathrm{BaTiO}_{3} \quad+15 \mathrm{wt} . \%\right.$ Silica $)$ nanoparticle to XLPE decreases the electric field distribution about $3.8 \%$ inside water sphere void, decreases the electric field distribution about $4.3 \%$ inside water cylinder void, decreases the electric field distribution about $4.1 \%$ inside water ellipse void and decreases the electric field distribution inside power cable insulation about $4.5 \%$ due to the effect of low dielectric constant and surface area of $\mathrm{BaTiO}_{3}$ and Silica nanoparticles.

Also, when adding concentration of (10wt.\% $\mathrm{BaTiO}_{3}$ ) nanoparticle to XLPE, electric stress inside cable insulator be in higher value than adding concentration of (10wt.\% $\mathrm{BaTiO}_{3}+15$ wt.\% Silica) nanoparticle to XLPE and other composite electric distribution assorted between them as shown in Fig.13. Electric stress distribution inside water cylinder void shown in Fig.14. Electric stress distribution inside water ellipse void shown in Fig. 15.

It has observed different behaviour to electric stress performance in case of adding multiple nanoparticles inside XLPE.

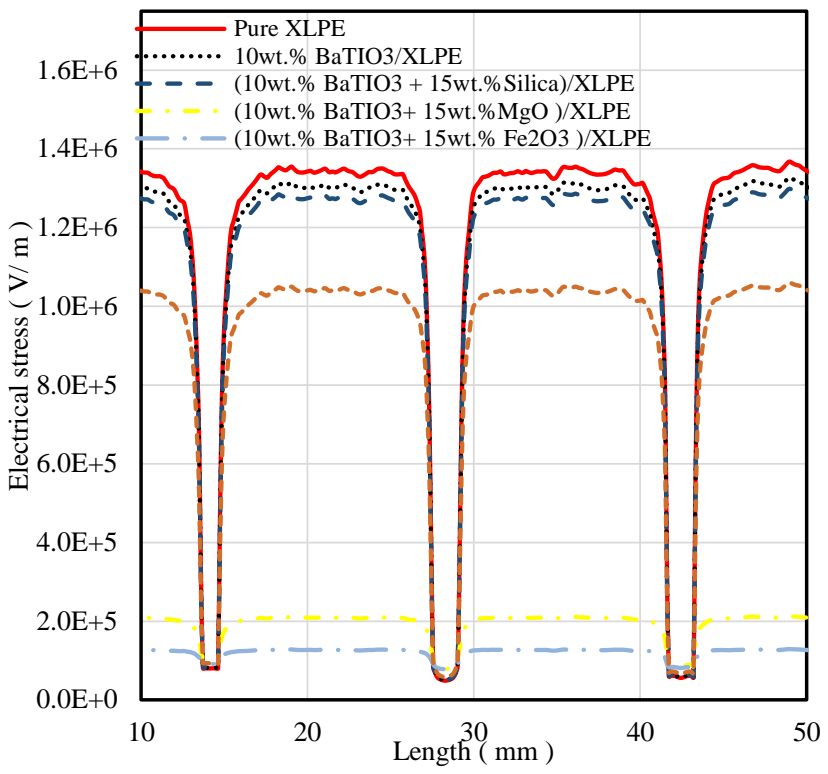

Fig. 13. Electric field distribution comparing pure XLPE with $\% \mathrm{BaTiO}_{3}$ nanoparticles insulation material containing different shapes of water voids

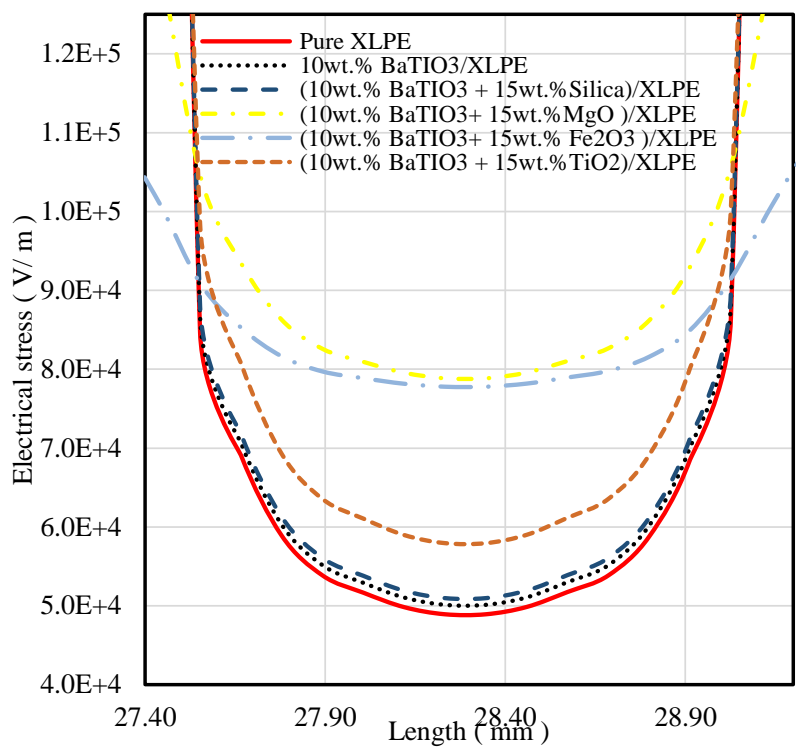

Fig. 14. Electric field distribution inside water cylinder void

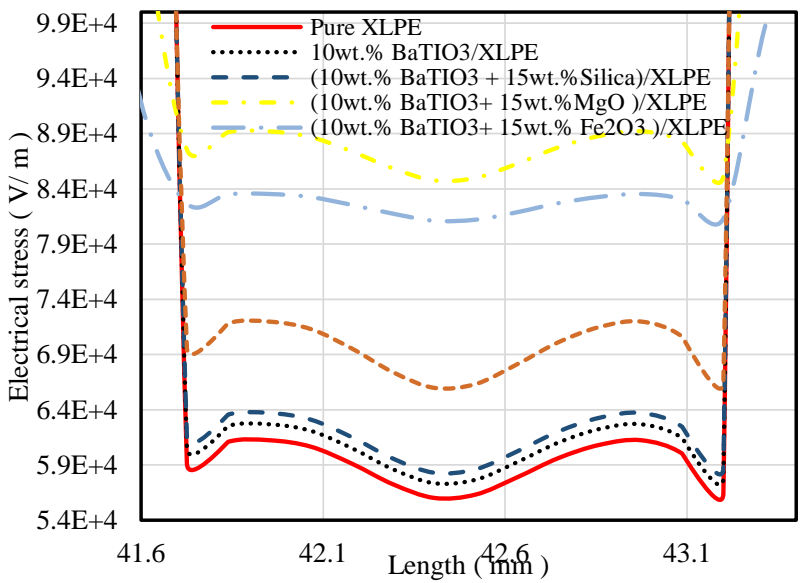

Fig. 15. Electric field distribution inside water ellipse void 


\section{Effect of Impurity Voids Shapes Inside Modern Nanocomposites Insulation}

Following figures illustrate the behaviour of electric stress within variant New Cross-linked polyethylene insulation materials pure and nanocomposites in case of presence different cupper impurity shapes in single core power cable.

It has been observed that adding concentration of (10wt.\% $\% \mathrm{Al}_{2} \mathrm{O}_{3}$ ) nanoparticle to XLPE has reduced the electric stress inside cable insulator than adding concentration of (10wt. $\% \mathrm{Al}_{2} \mathrm{O}_{3}+15$ wt.\% $\%$ Silica) nanoparticles to XLPE.

Electric stress distribution is drawn around core axis passes through impurity voids. It has been observed that adding concentration of $\left(10 \mathrm{wt} . \% \mathrm{Al}_{2} \mathrm{O}_{3}+15 \mathrm{wt} . \% \mathrm{Fe}_{2} \mathrm{O}_{3}\right)$ nanoparticle to XLPE increases the electric field distribution about $44.5 \%$ inside impurity sphere void, increases the electric field distribution about $69.2 \%$ inside impurity cylinder void, increases the electric field distribution about $61 \%$ inside impurity ellipse void and decreases the electric field distribution inside power cable insulation about $89.6 \%$ due to the effect of high dielectric constant and surface area of $\mathrm{Al}_{2} \mathrm{O}_{3}$ and $\mathrm{Fe}_{2} \mathrm{O}_{3}$ nanoparticles.

On the other side, it has been observed that adding concentration of (10wt. $\% \mathrm{Al}_{2} \mathrm{O}_{3}+15 \mathrm{wt} . \%$ Silica) nanoparticle to XLPE decreases the electric field distribution about $1.3 \%$ inside impurity sphere void, decreases the electric field distribution about $15.4 \%$ inside impurity cylinder void, decreases the electric field distribution about $9.9 \%$ inside impurity ellipse void and decreases the electric field distribution inside power cable insulation about $26.4 \%$ due to the effect of low dielectric constant ang surface area of Silica nanoparticle and other composite electric distribution graded between them as shown in Fig16.

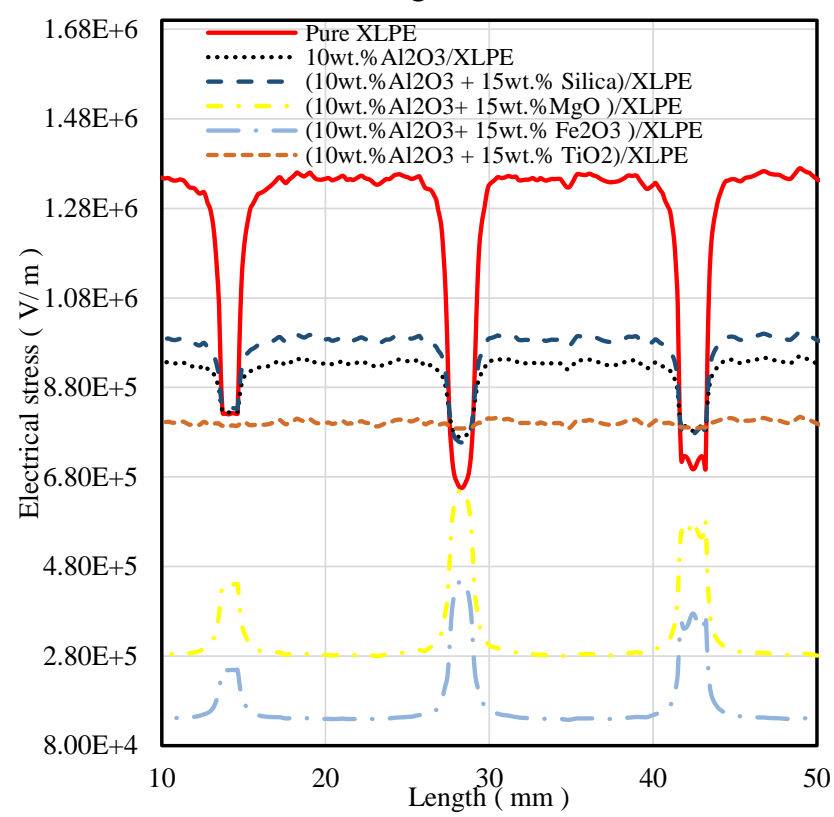

Fig. 16. Electric field distribution comparing pure XLPE with $\% \mathrm{AL}_{2} \mathrm{O}_{3}$ nanoparticles insulation material containing different shapes of cupper impurities voids

Whatever, it has been observed that adding concentration of $\left(10 \mathrm{wt} . \% \mathrm{BaTiO}_{3}+15 \mathrm{wt} . \% \mathrm{Fe}_{2} \mathrm{O}_{3}\right)$ nanoparticles to XLPE increases the electric field distribution about $45.2 \%$ inside impurity sphere void, increases the electric field distribution about $68.2 \%$ inside impurity cylinder void, increases the electric field distribution about $62.7 \%$ inside impurity ellipse void and decreases the electric field distribution inside power cable insulation about $90.5 \%$ due to the effect of high dielectric constant and surface area of $\mathrm{Fe}_{2} \mathrm{O}_{3}$ nanoparticle.

On the other side it has been observed that adding $\begin{array}{llll}\text { concentration of }(10 \mathrm{wt} . \% & \left.\mathrm{BaTiO}_{3} \quad+15 \mathrm{wt} . \% \text { Silica }\right)\end{array}$ nanoparticle to XLPE decreases the electric field distribution about $1.1 \%$ inside impurity sphere void, decreases the electric field distribution about $3.4 \%$ inside impurity cylinder void, decreases the electric field distribution about $2.5 \%$ inside impurity ellipse void and decreases the electric field distribution inside power cable insulation about $4.5 \%$ due to the effect of low dielectric constant and surface area of $\mathrm{BaTiO}_{3}$ and Silica nanoparticles. and other composite electric distribution graded between them as shown in Fig17.

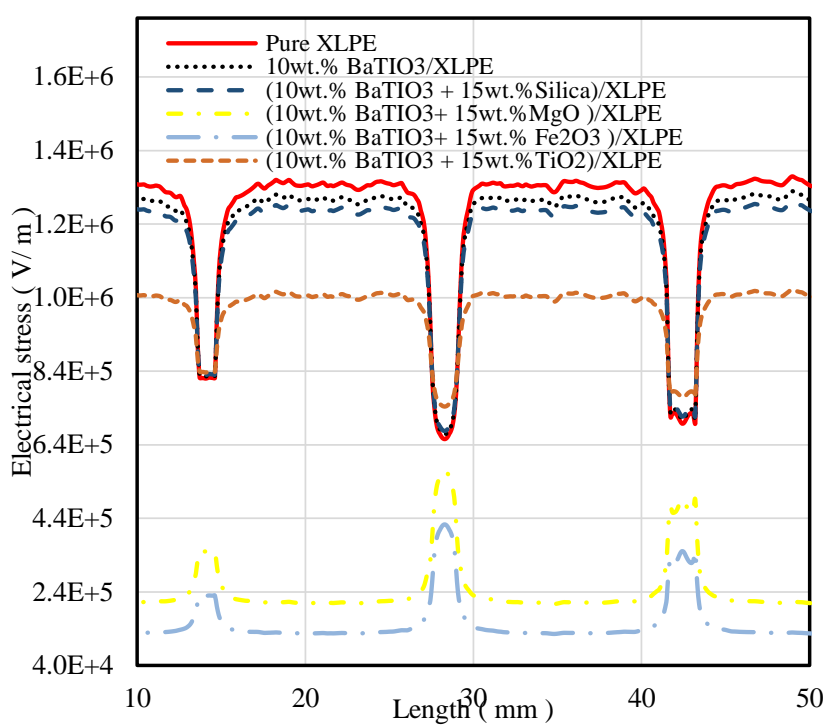

Fig. 17. Electric field distribution comparing pure XLPE with \% $\mathrm{BaTiO}$ nanoparticles insulation material containing different shapes of cupper impurities voids

Moreover, it has been observed that adding concentration of $\left(10 \mathrm{wt} . \% \mathrm{TiO}_{2}+15 \mathrm{wt} . \% \mathrm{Fe}_{2} \mathrm{O}_{3}\right)$ nanoparticle to XLPE increases the electric field distribution about $44.9 \%$ inside impurity sphere void, increases the electric field distribution about $70 \%$ inside impurity cylinder void, increases the electric field distribution about $61.6 \%$ inside impurity ellipse void and decreases the electric field distribution inside power cable insulation about $90.2 \%$ due to the effect of high dielectric constant and surface area of $\mathrm{Fe}_{2} \mathrm{O}_{3}$ nanoparticle.

On the other side, it has been observed that adding $\begin{array}{lllll}\text { concentration of } & (10 \mathrm{wt} . \% & \mathrm{TiO}_{2} & +15 \mathrm{wt} . \% & \left.\mathrm{BaTiO}_{3}\right)\end{array}$ nanoparticle to XLPE decreases the electric field distribution about $2.3 \%$ inside impurity sphere void, decreases the electric field distribution about $9.8 \%$ inside impurity cylinder void, decreases the electric field distribution about $6.8 \%$ inside impurity ellipse void and decreases the electric field distribution inside power cable insulation about $15 \%$ due to the effect of low dielectric constant of $\mathrm{BaTiO}_{3}$ and $\mathrm{TiO}_{2}$ nanoparticles. and other composite electric distribution assorted between them as shown in Fig. 18. 


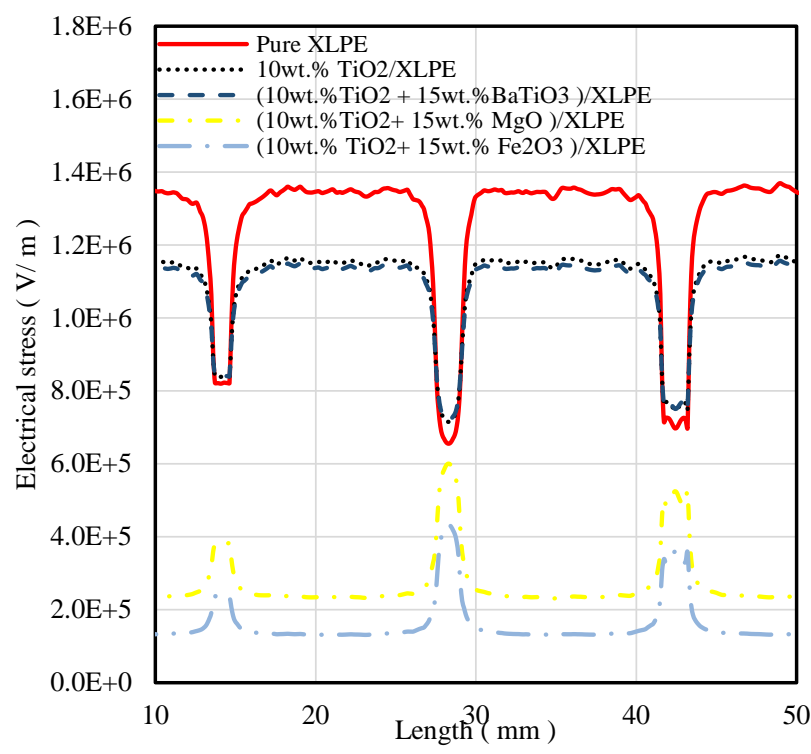

Fig. 18. Electric field distribution comparing pure XLPE with $\% \mathrm{TiO}_{2}$ nanoparticles insulation material containing different shapes of cupper impurities voids

\section{TRENDS OF MODERN NANOCOMPOSITES}

Nanotechnology techniques have been done to enhance the dielectrics of industrial applications by using individual and multiple nanoparticles [31-33]. TABLE III TABLE V show the comparing between electric stress inside voids and the effective nanocomposite materials. The current comparison has been done via different air voids, water void and cupper impurity shapes.

TABLE III. ELECTRIC STRESS IN SINGLE CORE CABLE CONTAINING DIFFERENT SHAPES OF AIR VOIDS

\begin{tabular}{|c|c|c|c|c|}
\hline \multirow{2}{*}{$\begin{array}{c}\text { Modern } \\
\text { Nanocomposites } \\
\text { Insulation } \\
\text { Material } \\
\end{array}$} & \multicolumn{4}{|c|}{ Air Voids Shapes E $(\mathrm{Kv} / \mathrm{m})$} \\
\hline & $\begin{array}{c}\text { Sphere } \\
\text { Void }\end{array}$ & $\begin{array}{c}\text { Cylinder } \\
\text { Void }\end{array}$ & $\begin{array}{c}\text { Ellipse } \\
\text { Void }\end{array}$ & $\begin{array}{c}\text { Inside } \\
\text { insulation }\end{array}$ \\
\hline PURE XLPE & $1.89 \mathrm{E}+3$ & $2.49 \mathrm{E}+3$ & $2.24 \mathrm{E}+3$ & $1.33 \mathrm{E}+3$ \\
\hline $\begin{array}{c}(10 \text { wt. } \% \\
\mathrm{Al}_{2} \mathrm{O}_{3}+15 \text { wt. } \% \\
\left.\mathrm{Fe}_{2} \mathrm{O}_{3}\right) / \text { XLPE }\end{array}$ & $2.76 \mathrm{E}+2$ & $6.20 \mathrm{E}+2$ & $4.42 \mathrm{E}+2$ & $1.38 \mathrm{E}+2$ \\
\hline $\begin{array}{c}\text { (10wt. } \% \mathrm{Al}_{2} \mathrm{O}_{3}+15 \mathrm{w} \\
\text { t. } \% \text { Silica }) / \text { XLPE }\end{array}$ & $1.57 \mathrm{E}+3$ & $2.42 \mathrm{E}+3$ & $2.04 \mathrm{E}+3$ & $9.78 \mathrm{E}+2$ \\
\hline $\begin{array}{c}\left(10 \mathrm{wt} . \% \mathrm{TiO}_{2}+15 \mathrm{wt} .\right. \\
\left.\% \mathrm{Fe}_{2} \mathrm{O}_{3}\right) / \mathrm{XLPE}\end{array}$ & $2.61 \mathrm{E}+2$ & $5.88 \mathrm{E}+2$ & $4.22 \mathrm{E}+2$ & $1.30 \mathrm{E}+2$ \\
\hline $\begin{array}{c}(10 w t . \% \\
\mathrm{TiO}_{2}+15 \text { wt. } \% \\
\left.\mathrm{BaTiO}_{3}\right) / \text { XLPE }\end{array}$ & $1.73 \mathrm{E}+3$ & $2.49 \mathrm{E}+3$ & $2.15 \mathrm{E}+3$ & $1.13 \mathrm{E}+3$ \\
\hline
\end{tabular}

TABLE IV. ELECTRIC STRESS IN SINGLE CORE CABLE CONTAINING DIFFERENT SHAPES OF WATER VOIDS

\begin{tabular}{|c|c|c|c|c|}
\hline \multirow{2}{*}{$\begin{array}{c}\text { Modern } \\
\text { Nanocomposites } \\
\text { Insulation } \\
\text { Material }\end{array}$} & \multicolumn{4}{|c|}{ Water Voids Shapes E (Kv/m) } \\
\hline & $\begin{array}{c}\text { Sphere } \\
\text { void }\end{array}$ & $\begin{array}{c}\text { Cylinder } \\
\text { void }\end{array}$ & $\begin{array}{c}\text { Ellipse } \\
\text { void }\end{array}$ & $\begin{array}{c}\text { Inside } \\
\text { insulation }\end{array}$ \\
\hline PURE XLPE & 79.8 & 48.9 & 59.1 & $1.33 \mathrm{E}+3$ \\
\hline $\begin{array}{c}(10 w t . \% \\
\mathrm{Al}_{2} \mathrm{O}_{3}+15 w t . \% \\
\left.\mathrm{Fe}_{2} \mathrm{O}_{3}\right) / \text { XLPE }\end{array}$ & 93.7 & 78.2 & 83.9 & $1.38 \mathrm{E}+2$ \\
\hline $\begin{array}{c}\left(10 \mathrm{wt} . \% \mathrm{Al}_{2} \mathrm{O}_{3}+15 \mathrm{w}\right. \\
\text { t. } \% \text { Silica }) / \text { XLPE }\end{array}$ & 95.4 & 59.6 & 71.5 & $9.77 \mathrm{E}+2$ \\
\hline $\begin{array}{c}\text { (10wt. } \% \mathrm{TiO}_{2}+15 w \mathrm{wt} \\
\left.\% \mathrm{Fe}_{2} \mathrm{O}_{3}\right) / \mathrm{XLPE}\end{array}$ & 92.1 & 77.9 & 83.0 & $1.30 \mathrm{E}+2$ \\
\hline $\begin{array}{c}(10 \text { wt. } \% \\
\mathrm{TiO}_{2}+15 \text { wt. } \% \\
\left.\mathrm{BaTiO}_{3}\right) / \text { XLPE }\end{array}$ & 89.1 & 55.2 & 66.4 & $1.13 \mathrm{E}+3$ \\
\hline
\end{tabular}

TABLE V. ELECTRIC STRESS IN SINGLE CORE CABLE CONTAINING DIFFERENT SHAPES OF IMPURITES VOIDS

\begin{tabular}{|c|c|c|c|c|}
\hline \multirow{2}{*}{$\begin{array}{c}\text { Manocomposites } \\
\text { Insulation } \\
\text { Material }\end{array}$} & \multicolumn{3}{|c|}{ Cupper Impurites Voids Shapes E (Kv/m) } \\
\cline { 2 - 5 } & $\begin{array}{c}\text { Sphere } \\
\text { void }\end{array}$ & $\begin{array}{c}\text { Cylinder } \\
\text { void }\end{array}$ & $\begin{array}{c}\text { Ellipse } \\
\text { void }\end{array}$ & $\begin{array}{c}\text { Inside } \\
\text { insulation }\end{array}$ \\
\hline PURE XLPE & 820 & 656 & 715 & $1.33 \mathrm{E}+3$ \\
\hline $\begin{array}{c}(10 \mathrm{wt} \% \\
\mathrm{Al}_{2} \mathrm{O}_{3}+15 \mathrm{wt} \% \\
\left.\mathrm{Fe}_{2} \mathrm{O}_{3}\right) / \mathrm{XLPE}\end{array}$ & 249 & 449 & 354 & $1.38 \mathrm{E}+2$ \\
\hline $\begin{array}{c}\left(10 \mathrm{wt} \% \mathrm{Al}_{2} \mathrm{O}_{3}+15 \mathrm{w}\right. \\
\text { t.\% } \% \mathrm{Silica}_{2} / \mathrm{XLPE}\end{array}$ & 831 & 757 & 786 & $9.78 \mathrm{E}+2$ \\
\hline $\begin{array}{c}\left(10 \mathrm{wt} \% \mathrm{TiO}_{2}+15 \mathrm{wt} .\right. \\
\left.\% \mathrm{Fe}_{2} \mathrm{O}_{3}\right) / \mathrm{XLPE}\end{array}$ & 236 & 432 & 339 & $1.30 \mathrm{E}+2$ \\
\hline $\begin{array}{c}(10 \mathrm{wt} \% \\
\mathrm{TiO}_{2}+15 \mathrm{wt} \% \\
\left.\mathrm{BaTiO}_{3}\right) / \mathrm{XLPE}\end{array}$ & 839 & 720 & 764 & $1.13 \mathrm{E}+3$ \\
\hline
\end{tabular}

\section{CONCLUSIONS}

- Adding nanoparticles to insulation material of power cable can changes the dielectric constant of insulation material weather effect in changing in self-capacitance of insulator then it is effect on the electric field distribution. Using individual nanocomposite materials and multinanocomposite material instead of pure XLPE insulation material decreases or increases the electric field distribution according to type and concentration of nanocomposite material.

- Adding multi-nanoparticles $\left(\mathrm{Al}_{2} \mathrm{O}_{3}\right.$ and $\left.\mathrm{Fe}_{2} \mathrm{O}_{3}\right)$ XLPE is deduced that their ability for reducing the electrostatic field distribution inside insulation of single core power cables. Whatever, adding nanoparticles (Silica and $\mathrm{BaTiO}_{3}$ ) is deduced that their ability for increasing the electrostatic field distribution inside insulation of single core power cables. It can be had more controlling in electrical properties and the electrostatic field distribution inside the insulation of single core power cables by using multi-nanoparticles technique.

- Adding concentration of $\left(10 \mathrm{wt} . \% \mathrm{Al}_{2} \mathrm{O}_{3}+15 \mathrm{wt} . \% \mathrm{TiO}_{2}\right)$ nanoparticles to XLPE has a high impact on stabilizing electrical field distribution through the effect of different shapes of cupper impurities inside insulation of single core cable which has used in this paper.

\section{ACKNOWLEDGEMENTS}

This work was supported by Nanotechnology Centre at Aswan University, Egypt, Grant No: Project ID 505.

\section{REFERENCES}

[1] M.Naidu, High voltage engineering, San Diego: CA, U.S.A., Bennett Books Ltd, 2008.

[2] A.Sabat and S. Karmakar, "Simulation of partial discharge in high voltage power equipment," International Journal on Electrical Engineering and Informatics, Vol. 3, Iss. 2, pp 234-247,2011.

[3] N.Ahmed and N. Srinivas, "Partial discharge severity assessment in cable system," Transmission and Distribution Conference and Exposition, Atlanta:IEEE/PES,pp 849-852,2001.

[4] G.Chen and F. Baharudin, "Partial discharge modelling based on a cylindrical model in solid dielectrics," International Conference on Condition Monitoring and Diagnosis, China: IEEE, pp 1-5,2008. 
[5] R.Lofaro and M. Villaran, "Essential Elements of an Electric Cable Condition Monitoring Program," Washington: Brookhaven National Laboratory, 2010.

[6] H.Jaarsveldt and R. Gouws, "Partial Discharge Simulations Used for the Design of a Non-Intrusive Cable Condition Monitoring Technique," Journal of Energy and Power Engineering, 2013, Vol. 7, pp 2193-2201.

[7] Li.Yanmu, Y. Liang, Y. Li, W. Si, P. Yuan and J. Li, "Coupled electromagnetic-thermal modeling the temperature distribution of XLPE cable," Power and Energy Engineering Conf, China: IEEE,pp $1-4,2009$.

[8] H.Illias, A., Z. H. Lee, A. H. A. Bakar, H. Mokhlis and A. M. Ariffin, "Distribution of electric field in medium voltage cable joint geometry," International Conference on Condition Monitoring and Diagnosis, Bali, Indonesia: IEEE,pp 1051-1054,2012.

[9] Y.Jiang, H. Min, J. Luo, Y. Li, X. Jiang, R. Xia and W. Li, "Partial Discharge Pattern Characteristic of HV Cable Joints with Typical Artificial Defect," Asia-Pacific Power and Energy Engineering Conference,Chengdu, China: IEEE,pp 2657-2661,2010.

[10] A.Thabet,'Experimental enhancement for dielectric strength of polyethylene insulation materials using cost-fewer nanoparticles," International Journal of Electrical Power \& Energy Systems (IJEPES), Vol. 64, pp 469-475,2015.

[11] A.Thabet, "Experimental Verification for Improving Dielectric Strength of Polymers by Using Clay Nanoparticles," Advances in Electrical and Electronic Engineering Journal,Vol.13, Iss. 2, pp 182$190,2015$.

[12] A.Thabet,"Thermal experimental verification on effects of nanoparticles for enhancing electric and dielectric performance of polyvinyl chloride," Journal of the International Measurement Confederation (IMEKO), Vol. 89, pp 28-33,2016.

[13] A.Thabet and Y.A. Mubarak, "Experimental Enhancement for Electric Properties of Polyethylene Nanocomposites under Thermal Conditions," Advances in Electrical and Electronic Engineering Journal,Vol. 15, Iss.1, pp 55-62,2017.

[14] A.Thabet and Y. A. Mubarak,"The Effect of Cost-Fewer Nanoparticles on the Electrical Properties of Polyvinyl Chloride," Electrical Engineering Journal, Springer,Vol. 99, Iss. 2, pp 625-631,2017.

[15] A.Thabet, and A.A. Ebnalwaled,"Improvement of surface energy properties of PVC nanocomposites for enhancing electrical applications," Journal of the International Measurement Confederation (IMEKO), Vol. 110, pp 78-83,2017.

[16] A.Thabet,"Theoretical Analysis for effects of nanoparticles on dielectric characterization of electrical industrial materials," Electrical Engineering (ELEN) Journal, Springer, Vol. 99, Iss. 2, pp 487-493, 2017.

[17] G.Mazzanti and M. Marzinotto, "Advanced Electro-Thermal Life and Reliability Model for High Voltage Cable Systems Including Accessories," IEEE Electrical Insulation Magazine,Vol. 33, Iss. 3, pp 17-25,2017.

[18] K.K.Karkkainen, A.H.Sihvola and K. I. Nikoskinen, "Effective Permittivity of Mixtures: Numerical Validation by the FDTD Method," IEEE Trans. Geoscience Remote Sensing,Vol. 38, Iss. 3, pp 13031308, 2000.

[19] K. K. Karkkainen, A. H. Sihvola and K. I. Nikoskinen, "Effective Permittivity of Mixtures: Numerical Validation by the FDTD Method", IEEE Trans. Geoscience Remote Sensing, Vol. 38, pp1303-1308, 2000.

[20] M. Todd and F. Shi, "Molecular Basis of the Interphase Dielectric Properties of Microelectronic and Optoelectronic Packaging Materials", IEEE Trans. Components Packaging Techn., Vol. 26, Iss. 3, pp 667-672, 2003.

[21] M. Todd and F. Shi, "Characterizing the Interphase Dielectric Constant of Polymer Composite Materials: Effect of Chemical Coupling Agents", J. Appl. Phys., Vol. 94, pp 4551-4557, 2003.

[22] A.Thabet and N. Salem, "Optimizing Dielectric Characteristics of Electrical Materials Using Multi-Nanoparticles Technique," International Middle East Power System Conference (MEPCON), EGYPT: IEEE, pp 220-225,2017.

[23] G.Polizos, E. Tuncer, I. Sauers and K. More,"Properties of a Nanodieletric Cryogenic Resin," Applied Physics Letter, Vol. 96, Iss 15, pp 152903-152903-3,2010.

[24] N.Tagami, M. Hyuga, Y. Ohki, T. Tanaka, T. Imai, M. Harada and M. Ochi, "omparison of Dielectric Properties between Epoxy Composites with Nanosized Clay Fillers Modified by Primary Amine and Tertiary
Amine," IEEE Dielectrics and Electrical Insulation Transactions, Vol. 17, Iss. 1, pp 214-220,2010

[25] Y.Yi and M. Sastry, "Analytical Approximation of the TwoDimensional Percolation Threshold for Fields of Overlapping Ellipses,” Phys. Rev. E,Vol. 66, pp 066130- 066138,2002.

[26] S . Avinash, K . Rajagopala, "Some Aspects of Stress Distribution and Effect of Voids Having Different Gases in MV Power Cables," IOSR Journal of Electrical and Electronics Engineering (IOSR - JEEE), Vol 5, Iss 6, pp 16-22, Jun. 2013.

[27] Nexans Energy Networks Company, 6-36kV Medium Voltage Underground Power Cables XLPE insulated cables catalogue, march 2010, Available at: https://www.nexans.co.uk.

[28] M.Alsharif, P.A.Wallace, D.M.Hepburn and C. Zhou, "Partial discharge resulting from internal degradation in underground MV cables: Modelling and analysis," 44th International Universities Power Engineering Conference (UPEC), Glasgow: IEEE, pp 1-4,2009.

[29] VEGA Grieshaber KG, List of dielectric constants catalogue, Available at: https://www.vega.com.

[30] K.Patel, A. Kumar and P. Kumar, "Electric Field Analysis of High Voltage Underground Cable using Finite Element Method," International Journal for Research in Applied Science \& Engineering Technology (IJRASET),Vol.7, Iss. 6, pp 1117-1122,2019.

[31] Ahmed Thabet Mohamed, "Design and Investment of High Voltage NanoDielectrics" IGI Global, Publisher of Timely Knowledge, ISBN13: 9781799838296, ISBN10: 1799838293, EISBN13: 9781799838302, DOI: 10.4018/978-1-7998-3829-6, Pages 363, August 2020.

[32] Z.M. Dang, J.K. Yuan, J.W. Zha, T. Zhou, S.T. Li, G.H. Hu, Fundamentals, processes and applications of high-permittivity polymerematrix composites, Prog. Mater. Sci. Vol. 57, pp. 660-723, 2012.

[33] K. Stojak, S. Pal, H. Srikanth, C. Morales, J. Dewdney, T. Weller, J. Wang, Polymer nanocomposites exhibiting magnetically tunable microwave properties, Nanotechnology, Vol. 22, pp. 135602, 2011. 
Faculty of Energy Engineering - Aswan University - Aswan - Egypt 